\title{
Corona Outbreak: Mental Health Implications of Lockdown and Quarantine due to Coronavirus spread
}

\author{
Nitin Sharma ${ }^{1 *}$, Liza Gupta ${ }^{1}$, Vikas Kumar ${ }^{2}$ \\ ${ }^{1}$ Departmentof Biotechnology, Chandigarh Group of Colleges, Landran, Mohali, Punjab, India \\ ${ }^{2}$ Faculty of Applied Sciences and Biotechnology, Shoolini University, Post Box No. 9, Head Post Office, Solan (H.P.), \\ India. \\ Email Id: abhinitu30@gmail.com
}

\begin{abstract}
Life, as all know, is not the same as before as coronavirus.This deadly disease has affected everything around the world. This pandemic is not only affecting people with pre-medical problems, but is also affecting healthy people. Mental health is an important asset which should be considered equally to physical health.Coronavirus has a significant impact on people's well-being and mental health. The shutdown and quarantine due to coronavirus has triggered worldwide terror, anxiety and depression. Loneliness, isolation and self-destructive behavior due to lack of support by close ones, increase in unemployment, low economy and many financial problems are specific reasons due to which mental problems are prevailing. Medical professionals around the world are involved in helping all the patients affected. Number of hospitals where insufficient facilities are available to resist the virus are at enormous mental stress. Many of the frontline staff who adhere to the government's directives and policies often suffer from emotional fatigue, while the public opposes certain laws. Besides all the ups and downs due to Coronavirus one must stand strong and cope with all the difficulties and fight this outbreak.Connecting with friends and loved ones, whether using high-tech or simple phone calls, can help keep our bond in stressful days and give strength to weather this tough journey.
\end{abstract}

Keywords- Corona virus; Mental Health; Social distancing; Lockdown; Depression; Connection (Keywords)

\section{INTRODUCTION}

Coronavirus is a deadly virus which has created emergency and health crisis globally. Coronavirus has created panic all around the world. This deadly virus is deeply concerned as the rate in increase of affected patients are triggering day by day. Coronavirus is one of the most difficult challenges faced by humans ever after World War II. Coronavirus has not only impacted physically; but has also disrupted on social, physical and mental levels as well.

Mental health is the well-being states of an individual in which individual realizes his own activities and fight with all the hurdles of the life [1]. Mental health includes the balance between the emotions and behavior. In this huge competitive world mental problems have taken a drastic change as one out of five people are suffering from anxiety, depression and other chronic mental problems.Mental health should also be considered equally important as physical health. Mental illness may get worse if they are left untreated. There can be various reasons for a person being mentally sick as it can include family history, trauma, and lack of communication. In this demanding world one has to take care of their body including the peace of mind. Mental problems can easily creep a person if it is left untreated. Stress can be normal sometimes but when it overcome one's mind and disrupts one's day to day function it is unhealthy. It is also found that when a person gets a drastic change around its surroundings which are unexpected can also be the reason for mental sickness. Just like this,coronavirus has also been an unexpected humanitarian challenge which is faced globally. From a fast pacing life to a complete halt there have been unforeseen changeslike quarantine and lockdown. Lockdown and quarantine have saved everyone physically but it has negative impact on the mental health of individuals. A recent large-scale study has shown that multifaceted public health interventions are temporarily linked to improved control of the COVID-19 pandemic [2]. Besides physical health, however, the potential psychological and mental health impact of the COVID-19 pandemic should also be taken seriously. Although previous research suggested that the mental impact of a major disaster has a wider and longer effect on people compared to physical injuries, mental health attracts far fewer planning and resources staff [3]. Previous studies conducted on the psychological effects associated with severe acute respiratory syndrome (SARS) which is similar to the COVID-19 pandemic, have identified severe psychological burdens on healthcare workers and the general public, such as anxiety, depression, panic attacks, or psychotic symptoms $[4,5]$. Health workers who had quarantine, worked in SARS units, or had family or friends infected with SARS had considerably more anxiety, depression, frustration, fear, and post-traumatic stress than those who had no such experience $[5,6]$. Several studies have reported about the high levels of psychological distress due to COVID-19 pandemic [7-22].The present review is an attempt to discuss all the possible factors affecting the mental health and the preventive measures to cope up with those factors in order to stay safe and healthy during this pandemic period.

\section{MENTAL STRESS DUE TO UNEMPLOYMENT DURING CORONA PANDEMIC}

Due to coronavirus, social distancing has been a major concern all around and to maintain the social distancing 
there have been certainlockdown and curfews worldwide accordingly the countries status of the cases of virus spread.Millions of people around the world are coping with job loss caused by the coronavirus disease 2019 (COVID19) pandemic. In a recent International Organization of Labor [23] which addresses the effects of the COVID-19 crisis, the young have already been marginalized in the workforce before the crisis. The recent emergence of significant loss of employment and increased work precariousness affects young people around the world in particular. The COVID-19 economic crisis with huge rises in jobs (and competition between workers) and the expected increase in digitalization will lead for some time to a substantial dislocation of young labor market workers [24].

Long-term lock-down triggers the unavailability of government services and the deterioration of many sectors, leading to a detrimental effect on local and national economic development $[25,26]$. This indicates that a significant number of citizens are losing income or are on the brink of unemployment and exacerbate their negative feelings during the COVID-19 pandemic [27]. COVID-19 has certainly made the biggest lock-down in civilization history that will massively increase these migrant workers' miseries, daily employment, and billions of slum residents around the world. Losing work leaving these people incapable at both ends and adds to their shame, anger, depression and mental illness this sudden tragedy at income insecurity leads to physical disability and higher suicide rates [28].

\section{MENTAL STRESS TO STUDENTS AMIDST LOCKDOWN}

In many countries the efforts made to curb the spread of COVID-19 among young people and adults have contributed to the comprehensive closing of schools, colleges, universities, and other educational institutions. As of March 25, 150 countries have closed schools and educational facilities worldwide, affecting more than 80 per cent of the world's student population. Several countries have introduced local school closures that are projected to be national [29]. Several countries have implemented localized school closures and those closures are expected to be nationwide [29]. Due to increased concerned towards COVID-19 pandemic, more and more universities across the globe have postponed or cancelled their events on the campus, for instance seminars, conferences, sports (intra-universities and interuniversities) and other activities. Universities quickly changed from face-to-face to online delivery for different courses and programs [30, 31].

Several studies documented the impact on the lives of students of the corona pandemic [32-35]. All these studies indicated that students, scientists and teachers have reported mild stress due to the closing of universities and colleges providing limited technical support and information that lead to uncertainties about the future of students, teachers and researchers. This pandemic puts pressure on students and teachers, while using limited resources, to adapt themselves to online education, leading to stress that is higher than usual.

\section{PLACEMENT FACTOR AFFECTING STUDENT'SMENTAL HEALTH}

When a person is busy in their daily chores their mindset is active but when something unexpected like lockdown and coronavirus exists, many are depressed and the same is with students they go to college and learn something new every daybut when the students are free and no interaction is their students are quite depressed thinking of their future. Students those were supposed to gets placements have been quite troubled and are anxious about future seeing the current scenario. The economic downturn has also affected the placement as many companies have backed offers due to coronavirus crisis and the students are quite depressed with this fact. Many summer internships have also been cancelled which discourages the students and burden them. The selected students are also going through hard times as the companies are cancelling the recruiter'sjob due to lockdown and work at halt. Students jobs are also quite under danger.Due to the crisis many companies have also reduced the pays of students due to which student find difficult to cope up with the peer pressure [36].

\section{INSTITUTIONS HELPING STUDENTS FOR ONLINE CLASSES AND CAMPUS PLACEMENTS}

Thus, to reduce the pressure, anxiety many institutions have been helping students amidst lockdown with all the study materialand also providing students with online classes as well. Many Colleges and Universities have been helping their students with onboard placements. From holding webinars and also requesting companies for online test rounds and online interviews colleges and universities are working very hard for their students to ensure that they get placements.Student must understand that their hard work is not wasted but the knowledge they have gained throughout is valuable and they must think positively that this lockdown period must be used as turning step and one must involve in learning new techniques and do work which they have never done and theirskills need to be polished and one must meditate and do exercises to relieve from stress and also stay fit and healthy. One must be physically as well as mentally stable and healthy.

\section{VI.STRESS DUE TO LOCKDOWN ENVIRONMENT}

Home is the only place where one feel happy, positive and safe especially during Coronavirus crisis, but sometimes the happy environment is not also positive. Older adults due to weak immune system may be more severe if they are infected and death toll is high in old aged as compared to younger generations. Older adults are more prone to coronavirus so they are supposed to be isolated as they have effete immunesystem and mostly have pre medical history. The adults suffering from cognitive decline may be more anxious and in stress and depression amidst quarantine. The older adults need more care and emotional support by the family members.The feeling of death amongst old age has created panic among many old adults thus this lead to stress and hypertension. According to many surveys it has been found that older people experienced more anxiety and stress than before lockdowns[37].

How can seniors helped to cope up stress amidst lockdown?

i. Psychologically attention must be paid to low educated female seniors as females are more 
emotional, widowed seniors, and seniors especially suffering from mental health problems.

ii. The physically unstable seniors must also be taken care properly and emotionally.

iii. Families must spend time together with the seniors so that sense of loneliness and emptiness may not emerge in them and they feel positive and loved.

\section{STRESS AMONGST CHILDREN DUE TO CORONA VIRUS}

The psychological impacts of the COVID-19 outbreak on young children and adolescents are likely to be very significant but apparently underestimated [38, 39]. Developmental psychological studies have been primarily designed to establish the basis for life-long conduct and accomplishment as a vital step for the development of cognitive, emotional and psycho-social skills during early childhood experience. During a serious pandemic such as COVID-19, community-based mitigation measures such as school openings, parks and play areas can interrupt the children's normal lifestyle. Both young and old children will possibly become more demanding, facing these changes, and may be anxious, frustrated and aggressive, which in turn will cause them to be subjected to overpressured parents' physical and mental abuse. Stressors, like monotony, disappointment, lack of face-to-face contact with classmates, friends and teachers, inadequate personal space at home, and family financial deprivation during lockdowns, all have the potential to cause problems and even sustained psychological adverse effects in children [38].

The interaction among their daily-routine changes, house arrest, and infection fear may exacerbate these unwanted mental reactions further and lead to a vicious cycle [38, 39, 40]. Remmerswaal et al. [41] has shown a significant correlation between parent's fear and children's fear with the H1N1 swine-flu pandemic in 2009. Similarly, children in the time of COVID-19 can develop phobia, post-traumatic stress disorder (PTSD), etc. through audiovisual media, including Social Media, after learning risk information, and other troubling details[38, 42]. Children with single parents or single parent (HCW), particularly those taking care of COVID-19 patients, can experience adjustment problems if a parent has to be quarantined [43, 44]. Momentary or prolonged separation between the parent and child can lead to an extended psychological effect and cause the child to be concerned about themselves and their loved ones.

\section{STRESS TO MEDICAL STAFFS AND FRONTLINE HEALTH WORKERS}

Coronavirus have obviously been war time Coronavirus have been declared pandemic in March 2020 and till then medical staff and all the frontline health workers are leaving no stone unturned to help cope up with this deadly virus. The adequate work load and excessive working hours have caused the sense of mental sickness to the medical staff and the workers. One more reason for being tensed among the workers is about transmission of infection increase within staff itself; this somewhere demotivates the medical staff and workers.
The increase in number of infected patients due to coronavirus and also increase in death toll indulges a fear of helplessness, frustration, adjustment issues and fear of discrimination among the medical staff. The distanced from their families and lack of emotional family support also creates a panic and anxiety among them. Health workers are not only handling patients but are also coping up with their mental health. Many doctors are now at verge of lack of patience and have feeling of being exhausted. The continuous wearing of PPE(Personal Protective Equipment) is also a challenging task for the staff and also make them feel suffocate. The PPE kit comprises of air tight material and still there is no guarantee of protection from the virus[45]. (https://www.medicalnewstoday.com/articles/covid-19medical-staff-experience-insomnia-and-higher-stress $\# 36 \%$ experience-insomnia).

The patients are rising day by day and workload is increasing. As the staff is less, some staff people are hitting the clock throughout the day to compensate the shortage of staff. This leads to hectic schedule and thus causes panic, helplessness and mental trauma among staff. Hospitals have also been major concern as beds of patients are limited and also the equipment provided is less as compared to patients. This has been a life-threatening situation for the medical health care workers. As the height of Coronavirus patients are increasing the medical staff has been working tremendously day and night because of which insomnia has been the key problem and insomnia is associated with sleep problems, depression, anxiety and helplessness.

To avoid the infection, medical staff could not eat and drink while wearing PPE kit which leads to dehydration due to excessive sweating and many develops rashes all around the body. Under such circumstances where one is surrounded by infected patients the staff feels depressed and a negative vibe is encircled all around which causes stress, anxiety and insomnia.Many citizens are safely working from home but still complaining about the pandemic but if we think about our medical workers and staff their fight mode have been on since the outbreak emerged and they sincerely perform their duties. Risking their lives all the medical staff is working against all the odds and helping their patients.We should also communicate with the doctors and all medical staff and boost up their confidence for handling such a situation tremendously.

\section{IX.FUTURE DIRECTIONS AND CONCLUSION}

Pandemic has though disturbed the living of people globally and everyone has different ways of tackling it but we must be emotionally strong. The government and stakeholders have to understand the psycho-social morbidity and the cost, deaths and related effects of this pandemic. Stigma and blame on the populations affected by the outbreak could hamper foreign trade, finance and relations, causing more unrest. There is a need for proper attention to eradicate disease-related stigma, bias, religious propaganda and psychosocial impact and a need for regular discussions with professional and qualified health workers by establishing task forces and management teams that are directly involved in healthcare systems without creating communication gaps between policymakers and ground 
lever. It is urgently needed to develop mental health organizations specializing in future pandemics with branches in many countries and individual health institutions to perform research, provide mental health services and coordinate awareness campaigns at both the personal and the community levels. The ongoing pandemic can be related to standardized websites and toll-free helpline numbers to help alleviate psychological anxiety in the general public. The social media should be used in a good way to inform people about patterns of transmission, disease symptoms and when effective medical consultations are required. Strict government laws and laws against false news, social media rumours, disinformation and misinformation must be enforced in order to protect social media against devaluations. The COVID-19 pandemic has made it clear to us that even in the 21 st century a "virus" can negatively impact our lives and has made us understand that health, peace, love, empathy, naivety and ignorance are the greatest assets of humanity. Taking care of family and friends can be a stress reliever and it should also be balanced with care of yourself too. Amidst lockdown virtual communication can also be stress buster and help cope up stress. We all are in this together and thus we have to be mentally, physically and socially strong throughout and fight against this deadly virus.

\section{REFERENCES}

[1] Galderisi S, $\underline{\text { Heinz A, Kastrup M, Beezhold J, and Sartorius }}$ N. Toward a new definition of mental health. World Psychiatry. 2015; 14(2): 231-233.

[2] Pan A, Liu L, Wang C, Guo H, Hao X, Wang Q. Association of Public Health Interventions with the Epidemiology of the COVID-19 Outbreak in Wuhan. JAMA. 2020;323:1915-1923.

[3] Allsopp K, Brewin CR, Barrett A, Williams R, Hind D, Chitsabesan P. Responding to mental health needs after terror attacks. BMJ. 2019;366.

[4] Maunder R, Hunter J, Vincent L, Bennett J, Peladeau N, Leszcz M. The immediate psychological and occupational impact of the 2003 SARS outbreak in a teaching hospital. CMAJ. 2003;168(10):1245-1251.

[5] Xiang YT, Yang Y, Li W, Zhang L, Zhang Q, Cheung T. Timely mental health care for the 2019 novel coronavirus outbreak is urgently needed. Lancet Psychiatry. 2020;7(3):228-229.

[6] Wu P, Fang Y, Guan Z, Fan B, Kong J, Yao Z. The psychological impact of the SARS epidemic on hospital employees in China: exposure, risk perception, and altruistic acceptance of risk. Can. J. Psychiat. 2009;54(5):302-311

[7] Lai J, Ma S, Wang Y, Cai Z, Hu J, Wei N. Factors associated with mental health outcomes among health care workers exposed to coronavirus disease 2019. JAMA Netw Open. 2020;3(3)

[8] Zhang SX, Liu J, Jahanshahi AA, Nawaser K, Yousefi A, Li J, Sun S. At the height of the storm: Healthcare staff's health conditions and job satisfaction and their associated predictors during the epidemic peak of COVID-19. Brain, Behavior, and Immunity. 2020 May 5.

[9] Zhu J, Sun L, Zhang L, Wang H, Fan A, Yang B. Prevalence and influencing factors of anxiety and depression symptoms in the first-line medical staff fighting against COVID-19 in Gansu. Front. Psychiatry. 2020;11:386.
[10] Chen Y, Zhou H, Zhou Y, Zhou F. Prevalence of selfreported depression and anxiety among pediatric medical staff members during the COVID-19 outbreak in Guiyang. Psychiatry Res. 2020;288

[11] Li W, Yang Y, Liu ZH, Zhao YJ, Zhang Q, Zhang L, Cheung T, Xiang YT. Progression of mental health services during the COVID-19 outbreak in China. International journal of biological sciences. 2020;16(10):1732.

[12] Lu W, Wang H, Lin Y, Li L. Psychological status of medical workforce during the COVID-19 pandemic: a cross-sectional study. Psychiatry Res. 2020;288

[13] Du J, Dong L, Wang T, Yuan C, Fu R, Zhang L. Psychological symptoms among frontline healthcare workers during COVID-19 outbreak in Wuhan. Gen. Hosp. Psychiatry. 2020

[14] Wang S, Xie L, Xu Y, Yu S, Yao B, Xiang D. Sleep disturbances among medical workers during the outbreak of COVID-2019. Occup. Med. (Lond.) 2020

[15] Zhang J, Lu H, Zeng H, Zhang S, Du Q, Jiang T. The differential psychological distress of populations affected by the COVID-19 pandemic. Brain, Behav. Immun. 2020

[16] Cao J, Wei J, Zhu H, Duan Y, Geng W, Hong X. A study of basic needs and psychological wellbeing of medical workers in the fever clinic of a tertiary general hospital in Beijing during the COVID-19 outbreak. PsychotherPsychosom. 2020:1-3.

[17] Tan BYQ, Chew NWS, Lee GKH, Jing M, Goh Y, Yeo LLL. Psychological impact of the COVID-19 pandemic on Health Care workers in Singapore. Ann Intern Med. 2020 doi: 10.7326/M20-1083.

[18] González-Sanguino C, Ausín B, Castellanos M, Saiz J, López-Gómez A, Ugidos C. Mental health consequences during the initial stage of the 2020 Coronavirus pandemic (COVID-19) in Spain. Brain Behav. Immun. 2020

[19] Nguyen HC, Nguyen MH, Do BN, Tran CQ, Nguyen TTP, Pham KM. People with suspected COVID-19 symptoms were more likely depressed and had lower health-related quality of life: the potential benefit of health literacy. J. Clin. Med. 2020;9(4):965.

[20] Zhou J, Liu L, Xue P, Yang X, Tang X. Mental Health response to the COVID-19 outbreak in China. Am. J. Psychiatry. 2020

[21] Kontoangelos K, Economou M, Papageorgiou C. Mental health effects of COVID-19 pandemia: a review of clinical and psychological traits. Psychiatry investigation. 2020 Jun; 17(6):491.

[22] Luo M, Guo L, Yu M, Wang H. The Psychological and Mental Impact of Coronavirus Disease 2019 (COVID-19) on Medical Staff and General Public-A Systematic Review and Meta-analysis. Psychiatry Research. 2020 Jun 7:113190.

[23] International Labor Organization World Employment and Social Outlook

Trends. 2020:2020a. https://www.ilo.org/global/research/gl obal-reports/weso/2020/lang--en/index.htm

[24] International Labor Organization. (2020b). Young workers will be hit hard by COVID-19's economic fallout. https://iloblog.org/2020/04/15/young-workers-willbe-hit-hard-by-covid-19s-economic-fallout/.

[25] Rubin GJ, Wessely S. The psychological effects of quarantining a city. Bmj. 2020 Jan 28;368.

[26] Pulla P. Covid-19: India imposes lockdown for 21 days and cases rise. BMJ. 2020;368:m1251

[27] Ho CS, Chee CY, Ho RC. Mental health strategies to combat the psychological impact of COVID-19 beyond paranoia and panic. Ann Acad Med Singapore. 2020 Jan $1 ; 49(1): 1-3$.

[28] Subbaraman R, Nolan L, Shitole T, Sawant K, Shitole S, Sood K, Nanarkar M, Ghannam J, Betancourt TS, Bloom DE, Patil-Deshmukh A. The psychological toll of slum 
CGC International Journal of Contemporary Technology and Research

living in Mumbai, India: a mixed methods study. Social Science \& Medicine. 2014 Oct 1;119:155-69.

[29] UNESCO. COVID-19 Educational disruption and response. (2020). Accessed: March 25, 2020: https://en.unesco.org/themes/educationemergencies/coronavirus-school-closures.

[30] Gewin V: Five tips for moving teaching online as COVID19 takes hold. Nature. 2020, [Epub ahead of print]:10.1038/d41586-020-00896-7

[31] THE. Will the coronavirus make online education go viral?. (2020). Accessed: March 24, 2020: https://www.timeshighereducation.com/features/willcoronavirus-make-online-education-go-viral.

[32] Sahu P. Closure of universities due to Coronavirus Disease 2019 (COVID-19): Impact on education and mental health of students and academic staff. Cureus. 2020.

[33] Cao W, Fang Z, Hou G, Han M, Xu X, Dong J, Zheng J. The psychological impact of the COVID-19 epidemic on college students in China. Psychiatry Research. 2020

[34] Law T. Medical workers fighting COVID-19 are facing a mental health crisis. (2020, April 17).Retrieved from https://time.com/5817435/covid-19-mental-healthcoronavirus/.

[35] Rehman U, Shahnawaz MG, Khan NH, Kharshiing KD, Khursheed M, Gupta K, Kashyap D, Uniyal R. Depression, Anxiety and Stress Among Indians in Times of Covid-19 Lockdown. Community mental health journal. 2020 Jun 23:1-7.

[36] https://m.timesofindia.com/city/madurai/final-yearstudents-worried-about-future-as-lockdownextends/amp_articleshow/75564634.cms.

[37] https://www.icrc.org/en/document/covid19-globalpandemic-may-increase-stress.

[38] Wang G, Zhang Y, Zhao J, Zhang J, Jiang F. Mitigate the effects of home confinement on children during the COVID-19 outbreak. The Lancet. 2020 Mar 21;395(10228):945-7.

[39] Ghosh R, Dubey MJ, Chatterjee S, Dubey S. Impact of COVID-19 on children: Special focus on psychosocial aspect. education. 2020;31:34.

[40] Sprang G, Silman M. Posttraumatic stress disorder in parents and youth after health-related disasters. Disaster medicine and public health preparedness. 2013 Feb 1;7(1):105-10.

[41] Remmerswaal D, Muris P. Children's fear reactions to the 2009 Swine Flu pandemic: The role of threat information as provided by parents. Journal of anxiety disorders. 2011 Apr 1;25(3):444-9.

[42] Muris P, Field AP. The role of verbal threat information in the development of childhood fear."Beware the Jabberwock!". Clinical Child and Family Psychology Review. 2010 Jun 1;13(2):129-50.

[43] Maunder R, Hunter J, Vincent L, Bennett J, Peladeau N, Leszcz M, Sadavoy J, Verhaeghe LM, Steinberg R, Mazzulli T. The immediate psychological and occupational impact of the 2003 SARS outbreak in a teaching hospital. Cmaj. 2003 May 13;168(10):1245-51.

[44] Dubey S, Dubey MJ, Ghosh R, Chatterjee S. Children of frontline COVID-19 warriors: Our observations. The Journal of Pediatrics. 2020 May 21.

[45] https://www.medicalnewstoday.com/articles/covid-19medical-staff-experience-insomnia-and-higher-stress\#36\%experience-insomnia. 